\title{
Prótesis total con reservorio salival en un paciente con síndrome de Sjögren*
}

\author{
Complete Denture with Salivary Reservoir in a Patient with Sjogren's Syndrome
}

Fecha de recepción: 27-02-2018 | Fecha de aceptación: 28-12-2018

\begin{abstract}
JiMMY MATIZ CUERVo
Universidad Nacional de Colombia. Bogotá, Colombia. matizc@unal.edu.co. https://orcid.org/0000-0001-5180-6555
\end{abstract}

*Descripción de un caso.

${ }^{\text {a} C}$ Correspondencia: jmatizc@unal.edu.co

doi: https://doi.org/10.11144/Javeriana.uo37-79.ptrs

Cómo citar: Matiz Cuervo J. Prótesis total con reservorio salival en un paciente con síndrome de Sjögren. Univ Odontol. 2018 jul-dic; 37(78). https://doi.org/10.11144/Javeriana.uo37-79.ptrs

\section{RESUMEN}

Antecedentes: El síndrome de Sjögren es una enfermedad autoinmune que empieza a manifestarse hacia los 45 años de edad y cuya incidencia aumenta con la edad. La sintomatología en la cavidad 
oral se caracteriza por boca seca o xerostomía. Gran cantidad de pacientes que la padecen son portadores de prótesis totales debido a la pérdida dental en edades avanzadas. Objetivo: Describir el caso de un paciente con síndrome de Sjögren a quien se le elaboró una prótesis con reservorio salival para disminuir síntomas orales. Métodos: Se realizaron ensayos de laboratorio para elaborar los reservorios buscando resistencia estructural de la prótesis; facilidad de colocación y retiro de las tapas de los reservorios para permitir la limpieza de los depósitos; estética y que contuvieran la mayor cantidad posible de saliva artificial. Los diseños se probaron en el paciente. Resultados: Después de realizar ensayos de prueba de la prótesis en ambos maxilares, el paciente comentó sobre la facilidad de retiro de las tapas, ausencia de nauseas, fonética normal, higiene adecuada, comodidad, solución parcial al problema de xerostomía y duración aproximada de tres horas una vez llenos los reservorios. Conclusión: Los prototipos finales proporcionaron mejores condiciones de los reservorios y aumentaron la cantidad de saliva. Se recomienda realizar estudios clínicos controlados para confirmar los hallazgos de este caso.

\section{Palabras clave}

diseño; enfermedad autoinmune; manejo protésico; prótesis total; reservorios salivales; síndrome de Sjögren; xerostomía

\section{Áreas temáticas}

odontología; paciente sistémicamente comprometido; rehabilitación oral 
Background: Sjögren's syndrome is an autoimmune disease that manifests after the age of 45 years and whose incidence increases with age. Symptoms in the oral cavity includes dry mouth or xerostomia. Large number of Sjögren's patients wear complete dentures due to tooth loss at advanced ages. Objective: To describe the case of a Sjögren's patient for whom dentures with salivary reservoirs were made to reduce oral symptoms. Methods: Lab tests were conducted to find an optimum denture design with reservoirs. Requirements included: structural resistance, easy placement and removal of reservoir caps to allow cleaning, good esthetics, and containing the greatest amount of artificial saliva. Models were tried in the patient. Results: Several models were tried for both jaws. At the end, the patient reported about easiness to remove caps, absence of nausea, normal phonetics, adequate hygiene, comfort, and partial solution to the problem of xerostomia with an approximate duration of three hours once the reservoir was full. Conclusion: Final prototypes provided the best characteristics of reservoirs and stored the highest amounts of saliva. It is important to conduct clinical controlled trials to confirm the findings of this case.

\section{Keywords}

autoimmune disease; complete denture; design; prosthetic management; reservoir; salivary reservoirs; Sjogren's syndrome; xerostomia

\section{Thematic fields}

dentistry; oral rehabilitation; systemically compromised patient

\section{INTRODUCCIÓN}


El síndrome de Sjögren es una enfermedad autoinmune, que afecta más a mujeres que a hombres, alterando glándulas exocrinas principalmente salivales con disminución subsiguiente del fluido salival. De cualquier forma el daño a los tejidos glandulares puede ser generalizado y difuso afectándose otros órganos del cuerpo (1).

Algunos profesionales lo denominan primario si solo afecta ojos y boca. Cuando, está asociado a otras enfermedades, se denomina síndrome de Sjögren secundario. Esta asociación con otros órganos del cuerpo es principalmente con la artritis reumatoide en primer lugar, y en otros casos con esclerodermia, lupus eritematoso sistémico, desordenes hematológicos, renales, pulmonares, pancreáticos, neurológicos y lo más grave el linfoma. Los síntomas y signos se manifiestan en la boca en forma de xerostomía o boca seca y en los ojos produciendo queratoconjuntivitis. Igualmente se produce resequedad vaginal importante y en casos severos resequedad extrema de la piel por fenómenos de vasculitis periférica. La determinación de los receptores nicotínicos y muscarínicos han permitido identificar que la alteración de la acetilcolina inhibe su acción sobre los receptores muscarínicos tipo 3 que son los responsables de estimular la secreción salival. Sin embargo la gravedad de la lesión sobre la glándula determina el grado de xerostomía del paciente (2).

Los efectos de la xerostomía son variados. En boca se aumentan las caries dentales por varios factores; el primero debido a que al disminuir la saliva se disminuye el efecto buffer de la saliva sobre los tejidos dentarios, en segundo lugar la población bacteriana se modifica y se altera el equilibrio microbiológico que favorece la producción de caries. En tercer lugar el efecto de 
autolisis conocido por los fisiólogos no surte su efecto en razón de la ausencia de saliva. La posibilidad de incrementarse las enfermedades periodontales es mayor dado el cambio en la microflora oral. Igualmente la resequedad oral impide una buena fluidez en el lenguaje; el efecto de lubricación y protección salival se ve disminuido; La protección de mucosas se ve disminuida impidiendo un asentamiento y una adaptación a las prótesis dentales y el gusto, se ve afectado.

El primer paso metabólico de los alimentos se afecta; la primera barrera bacteriana no se da; el proceso de la deglución también puede verse afectado, y finalmente se puede producir el síndrome de boca ardiente, donde hay dolor generalizado en mucosas $(3,4)$.

Los exámenes diagnósticos incluyen la sialometría, que consiste en la medición del flujo parotídeo, la cual se puede realizar en consultorio, recolectando la muestra en una probeta durante 5 minutos de saliva estimulada. La sialografía, que valora la calidad de los conductos y acinos glandulares; la ultrasonografía, que tiene una sensibilidad del $90 \%$ y su combinación con características clínicas muestra un $100 \%$ de eficiencia diagnóstica; la sialocintigrafía salival, la sialografía radiológica, la resonancia magnética, las tomografías computarizadas y la RM-sialografía (5).

En el tratamiento de la xerostomía se utiliza la Pilocarpina sustancia que ha demostrado efectos positivos de o a 30 minutos después de su ingesta. Aunque no presenta curación, sí otorga una mejoría en la cantidad de fluido salival ( $\mathrm{ml} / \mathrm{min}$.) durante períodos de tiempo relativamente interesantes (6). 
La cevimelina, que actúa una hora u hora y media después de su ingestión, provee estímulos receptores muscarínicos (3) y la duración de su efecto es de unas cinco horas.

La acupuntura se está utilizando con éxito importante en el manejo de pacientes con boca seca y en los últimos años está siendo aceptada por institutos americanos para tratar este síntoma. Uno de sus fundamentos científicos radica en que esta, incrementa la producción del polipéptido vasoactivo intestinal en saliva. (7).

Se utilizan dentífricos orales, enjuagues orales, saliva artificial, sustancias naturistas, etc. para aliviar los síntomas. La existencia de irrigadores nocturnos, de los piercing colocados en el labio inferior, de la férula intraoral de material blando, requieren de la conexión permanente del paciente a estos aparatos, limitando una vida de relación normal. También existen los dispositivos subclaviculares que consisten en un implante mandibular, pero son complejos, costosos, incómodos, requieren cirugía oral y subclavicular. El microirrigador CIQ que se coloca en la prótesis del paciente o en sus preparaciones dentarias, es antiestético, requiere conexión del paciente al irrigador y dificulta la deglución, la fonética y la comodidad del paciente $(8,9)$.

Se presenta el caso de un paciente a quien se le fabricó dentaduras completas superior e inferior, que contenían en su interior espacios que se pudieran llenar con de saliva artificial para ayudar a la lubricación oral de la boca del paciente durante el día, realizando sus actividades diarias normales, sin la sintomatología molesta de la xerostomía. 
En la revisión mundial sobre el tema de prótesis orales con depósitos salivales se encontraron pocas referencias con propuestas o modelos experimentales de prótesis orales. Vergo y Kadísh en 1981 presentaron un modelo experimental de prótesis con reservorio salival en pacientes desdentados después de irradiación, ellos utilizaron su modelo protésico en 6 pacientes con cáncer orofaríngeo quienes manifestaron alivio pasajero (10). En 1984, Vissink, gravenmade y col. Reportaron la elaboración de reservorios en dentaduras completas superior e inferior. Trabajaron con 8 pacientes, de los cuales 6 habían sido irradiados, I con síndrome de Sjögren y 1 con sialoadenitis crónica. Estos pacientes reportaron mejoría de la lubricación oral, en el llenado y limpieza relativamente fácil del reservorio (11). En 1984 Tolljanic y Zucuskie, presentaron dos reservorios palatinos en prótesis orales para tres pacientes. En este caso se reportan nauseas ocasionales, seseo en algunas palabras, pérdida o disminución del espacio intraoral (12). En 1986 Vissink, Huisman y Gravenmade, presentaron un modelo de prótesis con reservorio en el maxilar superior, pero la presentación deja entrever un trabajo de laboratorio muy dispendioso (13). En 1996, Sinclair, Verted y col, presentaron un reservorio salival en una prótesis mandibular. Estas prótesis las utilizaron dos pacientes durante periodos de 15 a 24 meses con buenos resultados. Se reportó una capacidad de 5,3 $\mathrm{ml}$ de saliva artificial con una duración de secreción de unas dos horas o más. Esta técnica es más prometedora y utiliza unos ajustes magnéticos (14). En 1997, Frost, Gardner y col. publican 3 modelos de prótesis diferentes para ofrecer a los pacientes depósitos salivales. Trabajaron con 11 pacientes que sufrían síndrome de Sjögren (15). En 2003, Mendoza y Tomlinson, reportan una nueva técnica con reservorio para prótesis mandibulares. Esta fue utilizada por un paciente con buen éxito, con mejor higiene, con buena capacidad del reservorio (16). 
Sin embargo, en todas estas propuestas quedan aspectos por solucionar como son la resistencia estructural de la prótesis, la estética, el acúmulo de alimentos, la facilidad de manipulación de la prótesis, el volumen salival y el contenido, entre otros.

\section{MATERIALES Y MÉTODOS}

Se elaboraron cuatro juegos de dentaduras completas, en los cuales se realizaron ensayos técnicos en la elaboración de los reservorios buscando siempre y cuando:

1. La resistencia estructural de la prótesis y en este sentido se utilizaron inicialmente reservorios en metal cromo-cobalto y siempre con acrílicos de alto impacto.

2. Sea fácil de colocar y retirar de las tapas de los reservorios por parte del paciente.

3. Las tapas puedan tener un sistema de retención firme y estable a lo largo del tiempo.

4. Permitan la higiene oral perfecta de los depósitos.

5. Sean absolutamente estéticas.

6. Contengan la mayor cantidad posible de saliva artificial.

En las cuatro dentaduras se colocaron diferentes tipos de cavidades en la zona palatina, con el objeto de evaluar cual podría contener mayor cantidad de saliva y fuera de fácil manejo para el paciente.

\section{RESULTADOS}


Inicialmente se realizaron varios ensayos para el reservorio en el maxilar superior (figura 1) los cuales presentaron dificultades técnicas en su elaboración, mínimo volumen salival, estimulo de reflejo nauseoso y fragilidad de las tapas en los reservorios.

FIGURA 1

A) Primer Ensayo. B) SEgundo EnSAyo. C) D) Tercer ensayo. E) CuARTo EnSAYo. F) Quinto ENSAYO
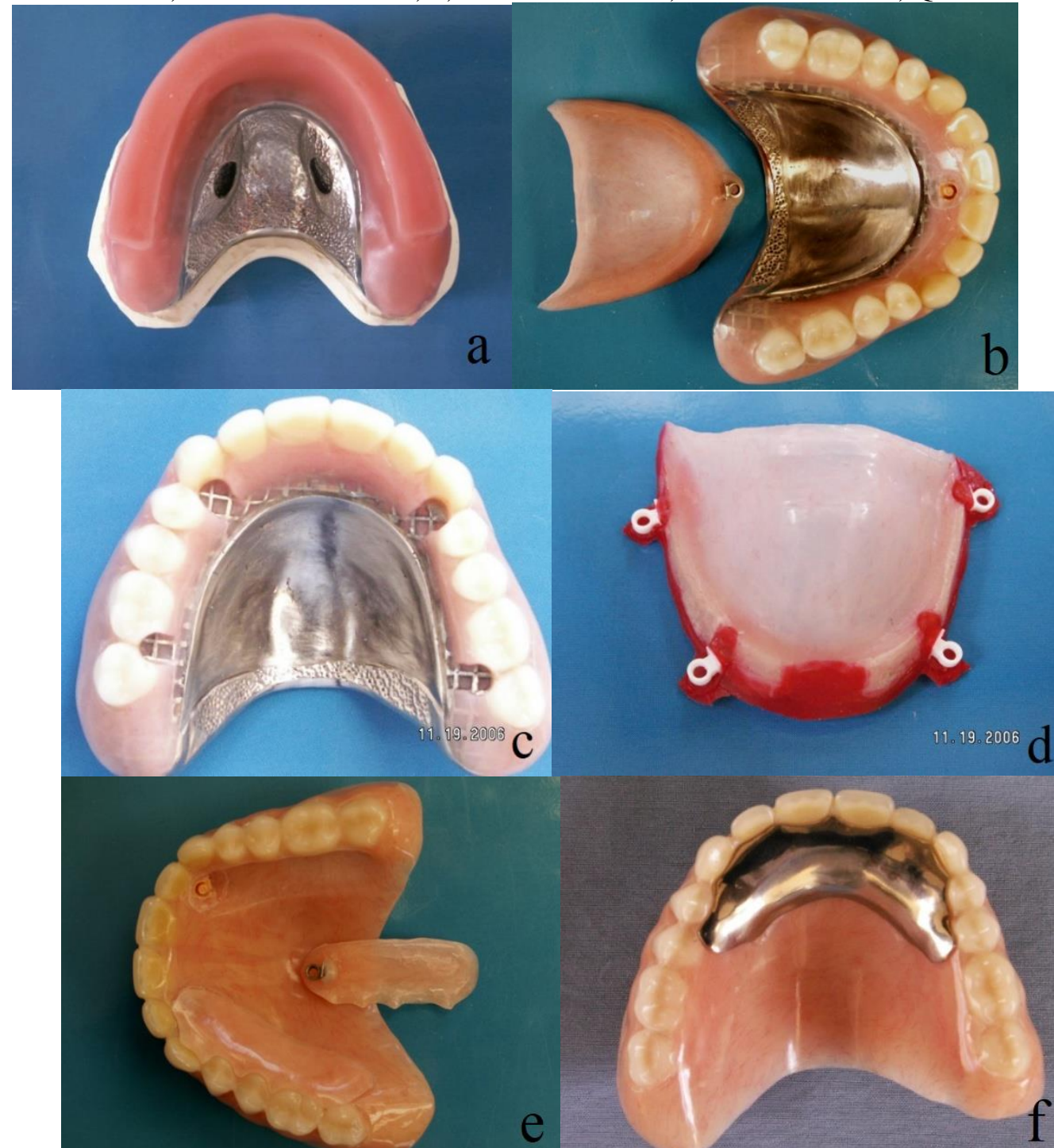

Para el último ensayo, se realizó una extensión con el depósito (cavidad), por debajo de todos los dientes formando un deposito en herradura que abarca desde el 16 o 17 hasta el 26 o 27 del otro 
lado del arco dental, obteniendo así un volumen importante de saliva artificial, cerca de 5c.c; para la retención se utilizan ahora tres ajustes del sistema ERA dos posteriores y uno anterior, o cuatro; dos en el sector posterior y dos en el sector anterior y la tapa del reservorio se fabricó en metal colado Remanium para obtener buena resistencia de la tapa del reservorio (figura 2).

Figura 2

a) Extensión total del reservorio. b) Tapa del reservorio

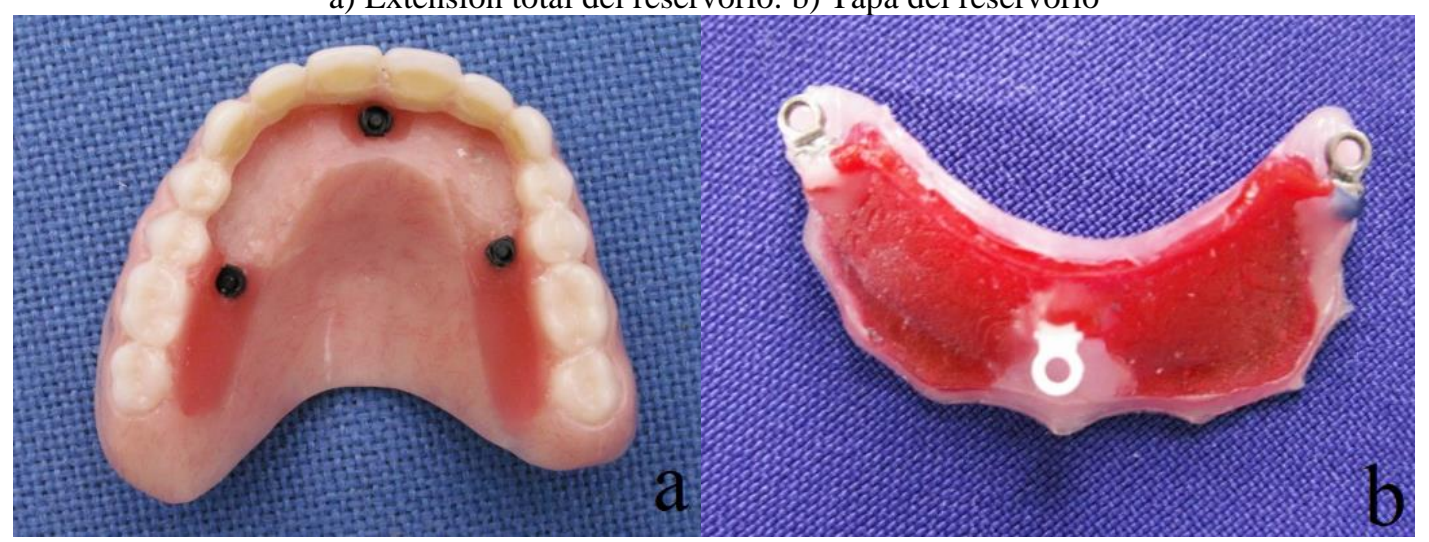

Para el maxilar inferior, la extensión del depósito (cavidad), se realizó por debajo de todos los dientes inferiores formando un depósito en que abarca desde el 33 a 37 y otro de 43 a 47 del otro lado del arco dental, obteniendo así un volumen importante de saliva artificial, cerca de 2,5 c.c. por reservorio; para la retención se utilizan ahora tres ajustes del sistema ERA dos posteriores y uno anterior o cuatro, dos en el sector posterior y dos en el sector anterior y la tapa del reservorio se fabrica en metal colado ofreciendo alta resistencia y perfecta higiene al paciente (figura 3).

FIGURA 3

A) RESERvorios. C) CAVIDADES DE 34 A 37. C) COLADO DE TAPAS METÁLICAS.D) AJUSTES ERA EN POSICIÓN. E) TAPAS CERRADAS 

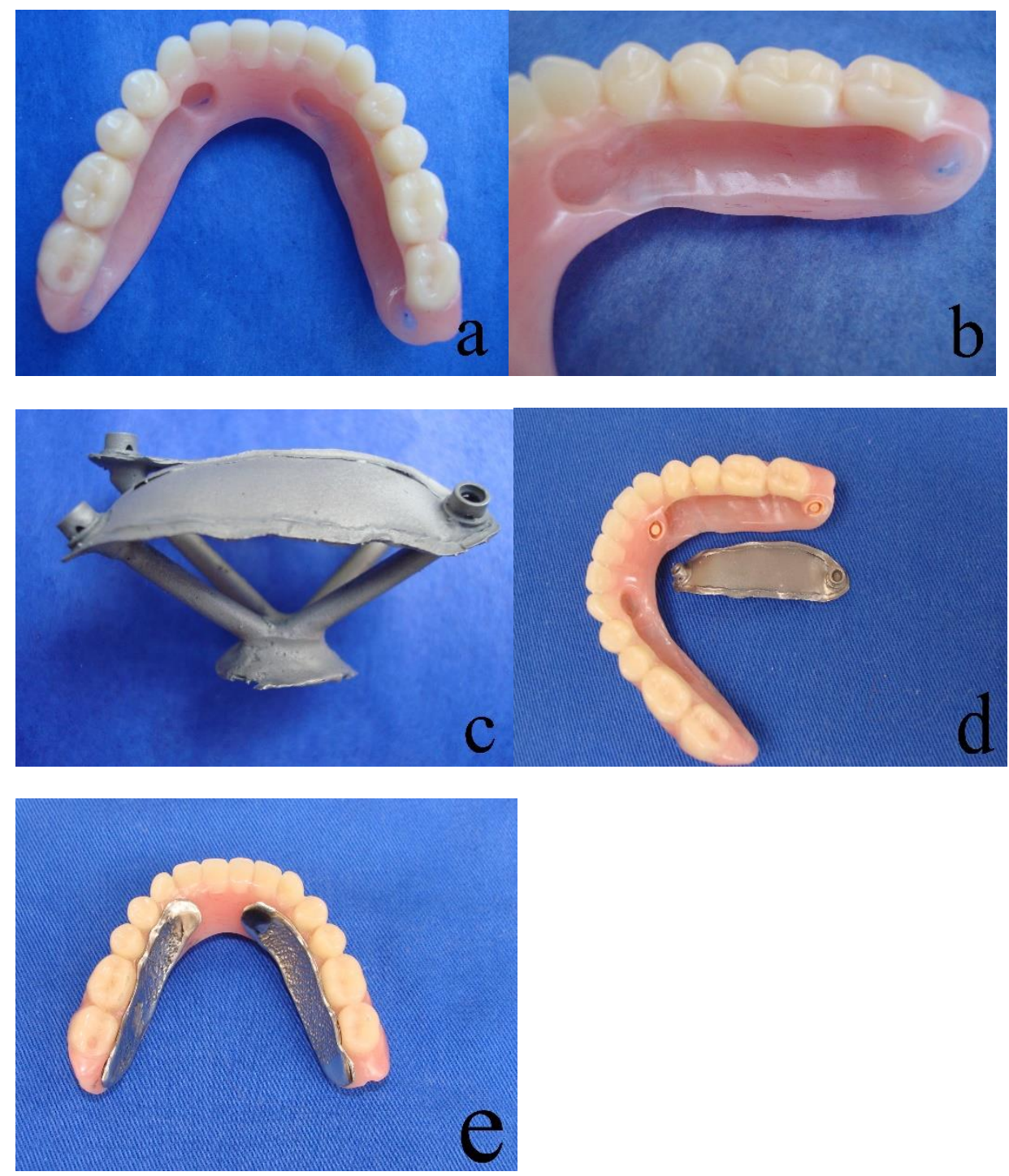

En los dos casos, las prótesis se terminan en su totalidad de acuerdo a las técnicas clásicas del acrilado dental y posteriormente se procede a retirar con fresas el acrílico necesario para realizar los socavados donde van lo depósitos salivales. Posteriormente se elaboran las tapas con matrices previamente diseñadas y se llevan a procedimientos de colado y finalmente se colocan en posición.

También es posible elaborar reservorios durante el proceso de enmuflado haciendo dos pasos adicionales; colocando silicona a manera de espaciador entre las dos capas de enmuflado y 
uniendo con acrílico de autocurado o fotocurado una de las partes del reservorio antes de su acrilado final, el cual le da mayor resistencia.

Se utilizaron ajustes tipo ERA para la fijación de las tapas que consisten en una unión machohembra, donde el macho viene calcinable y lo convertimos en metal y la hembra viene en presentación comercial en nylon de gran resistencia con diferentes grados de retención. El macho se fija en el reservorio y la hembra va en la tapa en la cual ajusta a manera de clip fuerte.

La paciente que participó en el estudio reporta facilidad en el retiro de las tapas, ausencia de nauseas, fonética normal, higiene adecuada, comodidad, solución parcial al problema de la xerostomía y duración aproximada de tres horas una vez lleno el reservorio. También comento las ventajas posibles de un sistema que utiliza la tecnología moderna para beneficio de los pacientes. Además indico que la succión realizada en su boca para humectar la boca es suave para no desocupar el reservorio en su totalidad.

Es de señalar que las tapas de los reservorios se dejan selladas aproximadamente un $90 \%$ de su extensión, permitiendo la salida de saliva en una cantidad pequeña pero justa para humectar la cavidad oral varias veces con un solo llenado del reservorio. 
A) CASO INICIAL. B) CASO TERMINADO, DESCRUZANDO SIMULTÁNEAMENTE LA OCLUSIÓN MEJORANDO A LA VEZ LA FUNCIÓN Y ESTÉTICA

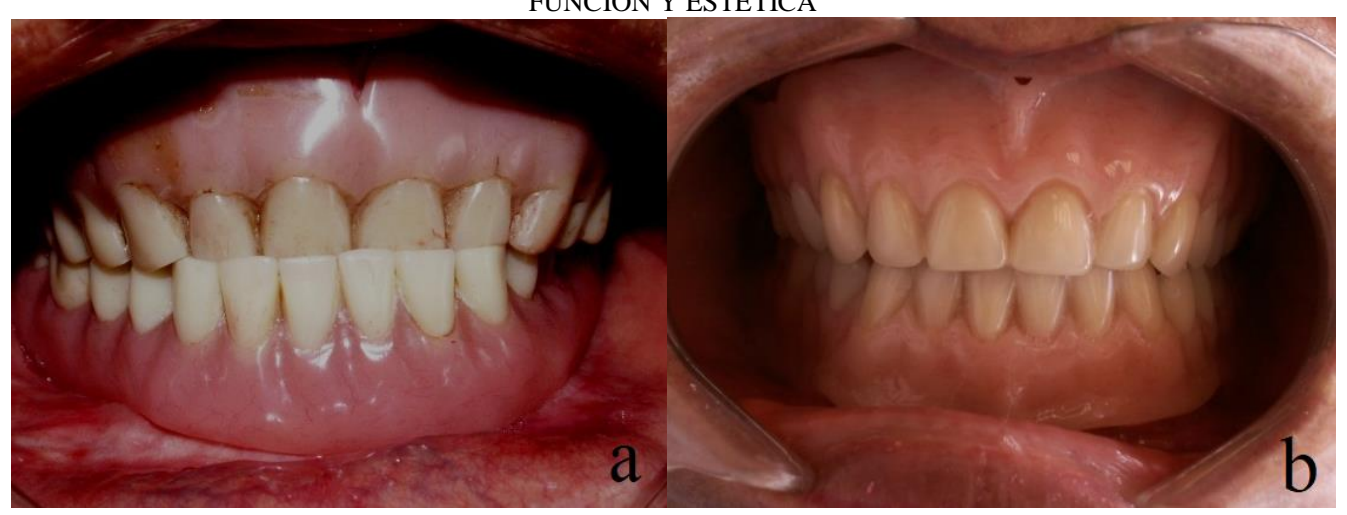

\section{DISCUSIÓN}

El síndrome de Sjögren es una enfermedad en incremento en el mundo entero por causas inmunológicas, incremento en la expectativa de vida y afecta más a mujeres que a hombres, ocasionando alteración de las glándulas salivales conllevando a la xerostomía oral como síntoma importante en todos los pacientes. Las técnicas protésicas para pacientes desdentados totales pueden ayudar a tratar los síntomas con la fabricación de reservorios internos en las dentaduras completas con liberación esporádica de sustitutos salivales aliviando los síntomas durante el día. El paciente tratado se seleccionó cuidadosamente ya que debe existir un buen espacio intermaxilar, una dimensión vertical adecuada para que el grosor de la prótesis no afecte 'por ejemplo la fonética. Además el paciente debe tener buena destreza motriz y una visión adecuada para manejar en buena forma sus prótesis con reservorio.

En esta técnica en particular fue fundamental el material de la tapa que cierra los reservorios ya que ofrece una resistencia excelente además de la utilización de ajustes de precisión tipo ERA, los cuales permiten una fijación adecuada. 
Es de esperar que con los avances en la odontología robótica o con técnicas de CAD-CAM, se puedan realizar reservorios en condiciones que permitan controlar la extensión del reservorio, calibrar sus paredes, y estandarizar guías de elaboración de reservorios que ayuden a los pacientes con síndrome de Sjögren o con xerostomía de diferentes orígenes.

Es importante También en futuros estudios trabajar de la mano con ingenieros que permitan elaborar sensores en las prótesis y permitan una liberación controlada de la saliva de acuerdo a las necesidades del paciente o bien la elaboración de bombas controladas de descarga de saliva sin necesidad de estar destapando los reservorios.

En cualquiera que sea el caso, es importante realizar ensayos clínicos que permitan desarrollar y validar técnicas que faciliten el manejo de la xerostomía oral.

\section{CONCLUSIONES}

Las ventajas de este sistema es la posibilidad de permanecer varias horas sin la necesidad de cargar botellas de agua o de enjuagues que incomodan a los pacientes.

Esta técnica permite un retiro seguro de las tapas de los reservorios con una cucharilla dental suministrada por el odontólogo.

Los reservorios son una medida complementaria excelente en los pacientes con síndrome de Sjögren grave. 
La selección del paciente es fundamental en el éxito del reservorio y por lo tanto se debe indicar en:

- $\quad$ Pacientes con xerostomía de cualquier origen.

- $\quad$ Pacientes con espacio intermaxilar amplio.

- $\quad$ Pacientes sin reflejo nauseoso aumentado.

- $\quad$ Pacientes con experiencia protésica.

- $\quad$ Pacientes con visión normal.

- $\quad$ Pacientes con síndrome de Sjögren, diabetes, irradiados, polifarmacia.

- $\quad$ Pacientes con habilidad manual normal.

- $\quad$ Pacientes motivados en su tratamiento.

\section{RECOMENDACIONES}

Se deben implementar otras técnicas con otros sistemas de broches o de bombas de liberación lenta que si bien no son para este tipo de trabajo se pueden acondicionar a este tipo de prótesis.

\section{REFERENCIAS}


1. Vitali C, Bombardieri S, Moutsopoulos HM, et al. Preliminary criteria for the classification of Sjögren's Syndrome. Results of a prospective concerted action supported the European Community. Arthritis Rheumatism. 1993; 36(3): 340-8.

2. Shiboski SC, Shiboski CH, Criswell LA, et al. American College of Rheumatology classification criteria for Sjögren's Syndrome: A data-driven, expert consensus approach in the Sjögren's International Collaborative Clinical Alliance Cohort. Arthritis Care Res. 2012; 64(4): 475-87.

3. Wolff S, Ofer M, Raviv, et al. The flow rate of whole and submandibular/sublingual gland saliva in patients receiving replacement complete dentures. J Oral Rehab. 2004; 3403.

4. Närhi TO, Meurman JH, Ainamo A. Xerostomia and hyposalivation: causes, consequences and treatment in the elderly. Drugs Aging. 1999; 15: 103-16.

5. Greenspan. Xerostomia: diagnosis and management. Oncol. 1996; 10: 7-11.

6. Gótrickl S, Akerman D, Ericson, et al. oral Pilocarpine for treatment of opioid-induced oral dryness in healthy adults. J Dent Res. 2004; 83(5): 393-7.

7. Dawidson B. Angmar-Mánsson M, Blom, et al. Sensory stimulation (acupuncture) increases the release of vasoactive intestinal polypeptide in the saliva of xerostomia sufferers. Neuropeptides. 1998; 32(6): 543-8.

8. Davies AN. A comparison of artificial saliva and chewing gum in the management of xerostomia in patients with advances cancer. Palliat Med. 2000; (14): 197-203.

9. Ilzarbe LM, Ilazarbe LM Jr, Villar D. Piercing canalizado, microirrigadores CIQ e implante hueco transfixivo para tratamiento de la xerostomía grave. Gaceta Dental: Industria y Profesiones. 2006; (169): 112-32. 
10. Vergo JT, Kadish P. Dentures as artificial saliva reservoirs in the irradiated edentulous cancer patient with xerostomia: A pilot study. Oral Surg. 1981; 51(3): 229-33.

11. Vissink A, Gravenmade EJ, Panders AK, et al. Artificial saliva reservoirs. J Prosthet Dent. 1984 Nov; 52: 710-5.

12. Toljanic JA, Zucuskie TG. Use of a palatal reservoir in denture patients with xerostomia J Prosthet Dent. 1984; 52: 540-4.

13. Vissink, MC Huisman, EJ Gravenmade. Construction of an artificial saliva reservoir in an existing maxillary denture. J Prosthet Dent. 1986; 56: 70-4.

14. Sinclair GF, Frost PM, Walter JD. New design for an artificial saliva reservoir for the mandibular complete denture. J Prosthetic Dent. 1996; 75: 276-80.

15. Frost PM, Gardner RM, Price AR et al. A preliminary assessment of intra-oral lubricating systems for dry mouth patients. Gerodontol. 1997; 14(1): 54-8.

16. Mendoza AR, Tomlinson MJ. The split denture: a new technique for artificial saliva reservoirs in mandibular dentures, Aust Dent J. 2003; 48: 190-4. 